\title{
Proteinograma de vacas leiteiras positivas para leucose enzoótica bovina e fasciolose
}

Sayanne Luns Hatum de Almeida, Natânia do Carmo Sperandio, Isabella Vilhena Freire Martins, Dirlei Molinari Donatele, Graziela Barioni", Ítalo Câmara de Almeida, Heberth de Paula, Yuri Barbosa Guerson, Renan Mello Spadetto, Lukas Souza Felisberto

Centro de Ciências Agrárias e Engenharias, Universidade Federal do Espírito Santo (UFES), Vitória, ES, Brasil

*Autor correspondente

e-mail: grazibari@gmail.com

\section{Resumo}

A leucose enzoótica bovina (LEB) e a fasciolose são enfermidades que manifestam-se de forma significativa nos rebanhos de vacas leiteiras na região do Caparaó, sul do estado do Espírito Santo. A LEB é uma doença infectocontagiosa de curso crônico, ocasionada pelo vírus da leucose bovina (BVL), retrovírus pertencente ao gênero Deltaretrovirus, responsável por imunossupressão no animal, uma vez que o BVL infecta preferencialmente linfócitos B. A fasciolose é causada por um trematoda da espécie Fasciola hepatica, parasito dos ductos biliares que também influencia na imunidade do animal, pois o órgão em questão exerce papel importante na regulação da resposta imune. Sendo assim, o presente trabalho buscou avaliar a imunidade humoral de animais com infecção concomitante por BVL e F. hepatica, por meio da avaliação do proteinograma por eletroforese em gel de poliacrilamida com duodecil sulfato de sódio (SDS-PAGE), a fim de estabelecer se há associação entre as enfermidades e o fator de risco entre as mesmas. Esse projeto foi aprovado pelo Comitê de Ética no Uso de Animais (CEUA - UFES) sob número 003/2015. Para isso, foram coletadas amostras de sangue de 142 vacas mestiças. 0 diagnóstico da LEB se deu por meio da técnica de imunodifusão em ágar gel (IDGA) utilizando-se o kit comercial com antígeno para diagnóstico de leucose enzoótica bovina da TECPAR ${ }^{\circledR}$, seguindo-se as recomendações do fabricante. A fasciolose foi diagnosticada por meio do ensaio imunoenzimático (ELISA), para a detecção de anticorpos direcionados contra a $F$. hepatica, utilizando-se o kit IDEXX FasciolosisVerification ${ }^{\circledR}$, seguindo-se as recomendações do fabricante. Do total dos animais analisados, houve prevalência de 50,7\% para fasciolose, 56,34\% para leucose e 29,57\% apresentaram infecção concomitante entre o BVL e a F. hepatica. Para a determinação da concentração da proteína total (PT) e albumina (ALB), foram utilizados kits comerciais da Bioclin ${ }^{\circledR}$ e LABTEST $^{\circledR}$, respectivamente; para a determinação das concentrações de globulinas (GLO), subtraiu-se a concentração de albumina do teor de proteína total. Diante disto, a partir dos valores encontrados, conclui-se que os níveis 
de PT, ALB e GLO não variaram significativamente entre o grupo controle, animais sadios e grupo de animais que cursaram a doença concomitantemente.

Apoio Financeiro: Fundação de Amparo à Pesquisa e Inovação do Espírito Santo (FAPES). 